\title{
The study of drug interaction on pneumonia patients at RSUP Dr. M. Djamil Padang
}

\section{Studi interaksi obat pada pasien balita dengan pneumonia di RSUP Dr. M. Djamil Padang}

\author{
Lola Azyenela ${ }^{*}$, Mimi Aria ${ }^{1}$, Lana Aristya ${ }^{1}$ \\ 1Prodi S1 Farmasi, Fakultas Farmasi, Universitas Perintis Indonesia, Padang, Indonesia \\ *Corresponding author: lolaazyenela2@gmail.com
}

\begin{abstract}
Background: Pneumonia is one of the diseases that cause high rates of toddler deaths in the world. In Indonesia, pneumonia is the second cause of death of infants and toddlers after diarrheal diseases. Most pneumonia patients are treated with other diseases so many pneumonia patients receive more than two types of drugs in one prescription, this has the potential for drug interactions with drugs.

Objective: The aim of this study was to look at potential occurrences of drug interactions in toddler patients at Dr.M. Djamil Padang Hospital hospitalized in 2019.

Methods: This research was nonexperimental research design with cross-sectional descriptive methods of analysis and the data retrieved retrospectively. The patient's medical records were analyzed using the Drugs.com software and Medscape.

Results: There were 62 patients who met the inclusion criteria. Among them, there were 5 pneumonia patients $(8.1 \%)$ who experienced drug interactions with drugs, with the pharmacokinetic category as many as 3 cases (42.9\%) affecting metabolism and drug interactions in the pharmacodynamic category by 4 cases $(57.1 \%)$. Based on the severity of drug interactions, this study found 1 minor case $(14.3 \%), 5$ moderate cases $(71.4 \%)$, and 1 major case $(14.3 \%)$.

Conclusion: From the results of the study it can be concluded that there was a potential for drug interactions in pneumonia toddler patients at Dr.M. Djamil Padang Hospital in the period 2019.

Keywords: Bronchopneumonia, drug Interactions, toddler
\end{abstract}

\section{Intisari}

Latar belakang: Pneumonia merupakan penyakit infeksi saluran pernapasan penyebab kematian utama pada balita di seluruh dunia. Di Indonesia, pneumonia menduduki peringkat kedua penyebab kematian bayi dan balita setelah diare. Pneumonia dapat disebabkan karena bakteri yang menyerang saluran pernapasan. Tatalaksana terapi pada pneumonia umumnya kombinasi beberapa obat. Hal ini berpotensi menimbulkan masalah pengobatan khususnya interaksi obat.

Tujuan: Penelitian ini bertujuan untuk melihat kejadian interaksi obat pada pasien balita di instalasi rawat inap anak RSUP Dr. M. Djamil tahun 2019.

Metode: Desain penelitian yang digunakan adalah cross-sectional deskriptif dengan pengambilan data secara retrospektif melalui rekam medis pasien. Setiap jenis obat yang tertulis rekam medis dianalisis dengan menggunakan bank data dari software Drug.com dan Medscape.

Hasil: Data diambil dari 62 pasien, berdasarkan jumlah tersebut dapat diidentifikasi 5 pasien mengalami interaksi obat (8,1\%), terdiri dari 71,4\% moderat, $14,3 \%$ minor dan $14,3 \%$ mayor.

Kesimpulan: Interaksi obat yang sering terjadi pada pasien balita dengan pneumonia adalah penggunaan kaptopril dengan furosemid.

Kata kunci: Balita, interaksi obat, pneumonia

\section{Pendahuluan}

Pneumonia merupakan penyebab utama kematian balita di dunia. Setiap tahun diperkirakan lebih dari 2 juta balita meninggal karena pneumonia. Data WHO melaporkan bahwa terdapat 156 juta kasus baru pneumonia anak diseluruh dunia, 61 juta kasus yang terjadi di 
wilayah Asia Tenggara (WHO, 2013). Di Indonesia, dari tahun 2015-2018 penemuan kasus pneumonia pada balita mengalami peningkatan sekitar 3\% dari 94,12\% menjadi 97,30\% (Kemenkes RI, 2018).

Tingginya morbiditas dan mortalitas pneumonia diberbagai negara berdampak pada penentuan strategi terapi bagi pasien. Penggunaan terapi yang tepat pada pasien akan menentukan keberhasilan terapi pneumonia. Terapi utama pada penanganan pneumonia adalah antibiotik yang ditujukan untuk mengeradikasi bakteri penyebab pneumonia. Selain penggunaan antibiotik, penderita pneumonia juga akan diberikan beberapa obat lainnya sebagai terapi pendukung guna mencapai keberhasilan terapi (Suharjono et al., 2009). Banyaknya penggunaan obat yang diberikan dapat menimbulkan permasalahan terapi pengobatan salah satunya adalah risiko interaksi obat. Interaksi obat adalah keadaan dimana, efek suatu obat diubah akibat adanya obat lain, semisal obat herbal, makanan, minuman atau agen kimia lainnya dalam suatu lingkungan (Baxter, 2008).

Permasalahan mengenai interaksi obat pada pasien rawat inap harus mendapatkan perhatian serius karena dapat meningkatkan toksisitas atau mengurangi efektivitas dari obat. Hasil penelitian Astiti (2017) menemukan ada 58,3\% pasien rawat inap yang mendapatkan efek samping merugikan yang disebabkan oleh interaksi obat (Saula, 2019). Informasi mengenai interaksi obat akan membantu tenaga kesehatan untuk mengidentifikasi dan mencegah reaksi yang tidak dikehendaki dari penggunaan obat serta meningkatkan patient safety. Penelitian mengenai interaksi obat sudah banyak dilakukan namun sebagian besar dilakukan untuk pasien dewasa, sedangkan penelitian pada anak-anak masih terbatas. Penelitian ini bertujuan untuk melihat kejadian interaksi obat pada pasien balita dengan pneumonia di Instalasi Rawat Inap Anak RSUP Dr. M. Djamil Padang.

\section{Metode}

\subsection{Jenis dan desain penelitian}

Penelitian ini merupakan penelitian non-eksperimental, dengan menggunakan rancangan cross-sectional deskriptif dan pengambilan data secara retrospektif dari bulan Januari hingga Desember 2019. Penelitian ini telah mendapatkan persetujuan kelaikan etik (ethical clearance) dari Komite Etik Penelitian Kesehatan RSUP Dr. M. Djamil Padang, dengan Nomor 223/KEPK/2020 dan izin penelitian dari Direktur Utama RSUP Dr. M. Djamil Padang.

\subsection{Populasi dan sampel penelitian}

Populasi dalam penelitian ini adalah semua pasien anak yang dirawat inap, dan didiagnosa pneumonia di RSUP. Dr. M. Djamil Padang. Sampel pada penelitian ini adalah semua pasien anak yang dirawat inap dan didiagnosa pneumonia di RSUP.Dr. M. Djamil Padang pada 
tahun 2019 yang memenuhi kriteria inklusi yaitu pasien usia balita ( $0-5$ tahun) dan pasien yang mendapatkan minimal 2 jenis item obat dan menjalani rawat inap di RSUP Dr. M. Djamil Padang pada tahun 2019, dengan teknik sampling adalah total sampling.

\subsection{Analisa Data}

Data dianalisa dengan menggunakan software Drugs.com yang terdapat pada website https://www.drugs.com/drug_interactions.html dan Medscape.com di https://reference.medscape.com/drug-interactionchecker, untuk melihat interaksi obat yang terjadi. Data interaksi obat di analisa secara deskriptif, serta dilakukan pengelompokan jenis interaksi obat yang terjadi beserta tingkat keparahannya.

\section{Hasil dan pembahasan}

Pada bulan Januari sampai Desember 2019, terdapat 88 pasien balita yang terdiagnosa pneumonia di RSUP Dr. Djamil Padang, namun 19 data pasien diekslusi karena ada informasi didalam rekam medis tidak terbaca dan terisi dengan lengkap sehingga diperoleh 69 data pasien yang memenuhi kriteria inklusi penelitian. Berdasarkan data karakteristik pada Tabel 1 menunjukkan bahwa pasien laki-laki lebih banyak yaitu 66,67 \% dibandingkan perempuan. Beberapa penelitian melaporkan bahwa persentase pasien laki-laki yang didiagnosa pneumonia lebih banyak dari pada pasien perempuan, seperti penelitian Kaunang CT (2016) di RSUP Prof. Dr. R. D. Kandou Manado periode 2013-2015 yang melaporkan dari 158 kasus anak, sebanyak $(55,7 \%)$ adalah pasien laki-laki. Begitu juga halnya dengan penelitian lain melaporkan bahwa dari 83 kasus pneumonia pada anak, 67,5\% diantaranya adalah pasien laki-laki (Balakrishnan, 2014). Jenis kelamin merupakan salah satu faktor resiko penyakit pneumonia, menurut Sunyataningkamto anak laki-laki lebih beresiko menderita pneumonia, karena ukuran saluran pernapasan anak laki-laki lebih kecil dibandingkan anak perempuan serta daya tahan tubuh anak perempuan lebih tinggi dibandingkan laki-laki (Hartati, 2012).

Sementara itu, berdasarkan usianya, didominasi pada usia 1 sampai 12 bulan (63,77\%). Usia kurang dari 1 tahun memiliki kekebalan tubuh yang belum sempurna, sehingga berpotensi lebih besar untuk terpapar penyakit saluran pernafasan diantaranya pneumonia. Saluran pernfasan yang belum sempurna menyebabkan meningkatnya jumlah bakteri patogen pada saluran pernafasan. Hasil penelitian menyatakan bahwa sebanyak 48\% usap tenggorokan pada anak usia kurang dari 2 tahun terdapat bakteri Streptococcus pneumoniae, yang merupakan bakteri utama penyebab pneumonia (Price et al., 2006 ; Soewignjo et al., 2001).

Tabel 1. Karakteristik umum pasien

\begin{tabular}{lc}
\hline Karakteristik & Jumlah (\%) \\
\hline $\begin{array}{l}\text { Jenis Kelamin } \\
\text { Laki-laki }\end{array}$ & $46(66,67)$
\end{tabular}


131 | Azyenela, L., dkk /Jurnal Ilmiah Farmasi (Scientific Journal of Pharmacy) Special Edition 2022, 128135

\begin{tabular}{lc}
\hline Karakteristik & Jumlah (\%) \\
\hline Perempuan & $23(33,33)$ \\
\hline Umur & $44(63,77)$ \\
1-12 bulan & $18(26,09)$ \\
13-24 bulan & $4(5,79)$ \\
$25-36$ bulan & $3(4,35)$ \\
$37-48$ bulan & \\
\hline Jumlah Obat per Pasien & $48(69,56)$ \\
$2-5$ & $20(28,98)$ \\
$6-8$ & $1(1,44)$ \\
$>8$ & $8(11,59)$ \\
\hline Lama Rawatan & $39(56,52)$ \\
$<5$ hari & $22(31,88)$ \\
$5-10$ hari & $10(14,49)$ \\
$>10$ hari & $25(36,23)$ \\
\hline Jumlah Penyakit Penyerta & $34(49,27)$ \\
Tanpa penyakit penyerta & \\
\hline $1-3$ & 3
\end{tabular}

Jumlah item obat dalam satu resep adalah salah satu faktor yang penyebab terjadinya interaksi obat, pada penelitian ini sebagian besar jumlah obat yang diterima pasien berkisar antara 2 sampai 5 item obat (69,56\%) per pasien. Penggunaan obat yang lebih dari 3 jenis obat perpasien akan meningkatkan risiko terjadinya interaksi obat. Hal ini menunjukkan terjadinya polifarmasi dengan kategori minor. Polifarmasi kategori minor ditandai dengan adanya 2 sampai 4 obat dalam satu lembar resep (Herdaningsih S, 2016). Sebanyak 34 orang pasien $(49,27 \%)$ memiliki lebih dari 3 penyakit lain selain penyakit bronkopnemonia, diantaranya adalah penyakit penyakit jantung bawaan sianotik, hipotiroid kongenital, syndrome down, hernia umbilikalis, sindrom epilepsy, cerebral palsy dan penyakit lainnya.

Tabel 2. Pola penggunaan obat pada pasien balita dengan pneumonia di RSUP Dr. Djamil Padang pada

\begin{tabular}{|c|c|c|c|}
\hline No & $\begin{array}{c}\text { Terapi obat yang diterima pasien } \\
\text { selama rawatan }\end{array}$ & $\begin{array}{l}\text { Jumlah } \\
\text { (f) }\end{array}$ & Persentase (\%) \\
\hline 1. & Ambroxol & 8 & 3,11 \\
\hline 2. & Ampicillin & 63 & 25,7 \\
\hline 3. & Azitromisin & 5 & 1,94 \\
\hline 4. & Sefiksim & 2 & 0,77 \\
\hline 5. & Sefotaksim & 1 & 0,38 \\
\hline 6. & Seftazidim & 1 & 0.38 \\
\hline 7. & Seftriakson & 7 & 2,72 \\
\hline 8. & Deksametason & 35 & 13,61 \\
\hline 9. & Gentamicin & 50 & 19,45 \\
\hline 10. & Kloramfenikol & 16 & 6,22 \\
\hline 11. & Meropenem & 4 & 1,55 \\
\hline 12. & $\mathrm{~N}-$ asetilsistein & 2 & 0,77 \\
\hline 13. & Parasetamol & 40 & 15,56 \\
\hline 14. & Vankomisin & 1 & 0.38 \\
\hline 15. & Kaptopril & 7 & 2,72 \\
\hline 16. & Furosemid & 7 & 2,72 \\
\hline
\end{tabular}




\begin{tabular}{llcc}
\hline No & $\begin{array}{c}\text { Terapi obat yang diterima pasien } \\
\text { selama rawatan }\end{array}$ & $\begin{array}{c}\text { Jumlah } \\
(\boldsymbol{f})\end{array}$ & Persentase (\%) \\
\hline 17. & Fenobarbital & 4 & 1,55 \\
18. & Spironolakton & 4 & 1,55 \\
\hline \multicolumn{2}{c}{ Total } & $\mathbf{2 5 7}$ & $\mathbf{1 0 0}$ \\
\hline
\end{tabular}

Dari Tabel 2 dapat dilihat bahwa antibiotik yang paling banyak digunakan untuk pasien balita dengan pneumonia adalah ampicillin sebanyak 40,94\%. Ampicillin merupakan antibiotik lini pertama untuk bayi dengan umur lebih dari 2 bulan (Pedriatric, 2012). Menurut Ikatan Dokter Anak Indonesia (IDAI), amoksisilin merupakan antibiotika pilihan pertama untuk anak usia kurang dari 5 tahun karena efektif melawan sebagian besar patogen yang menyebabkan pneumonia pada anak, ditoleransi dengan baik dan murah, selain itu penggunaan antibiotik ampisillin juga dianjurkan untuk terapi empirik pada anak (IDAI, 2009).

Tabel 3. Distribusi kejadian interaksi obat pada pasien balita pnemonia berdasarkan jenis interaksi dan tingkat keparahan

\begin{tabular}{|c|c|c|c|c|}
\hline No & Interaksi obat & Jenis interaksi & $\begin{array}{c}\text { Tingkat } \\
\text { keparahan }\end{array}$ & Jumlah \\
\hline 1. & $\begin{array}{l}\text { Kaptopril dan } \\
\text { Furosemid }\end{array}$ & $\begin{array}{l}\text { Farmakodinamik: } \\
\text { Meningkatkan efek hipotensi } \\
\text { (drugs.com) }\end{array}$ & Moderate & 2 \\
\hline 2. & $\begin{array}{l}\text { Kaptopril dan } \\
\text { Asetozolamid }\end{array}$ & $\begin{array}{l}\text { Farmakodinamik: } \\
\text { Meningkatkan efek hipotensi } \\
\text { (drugs.com) }\end{array}$ & Moderate & 1 \\
\hline 3. & $\begin{array}{l}\text { Kaptopril dan } \\
\text { Spironolakton }\end{array}$ & $\begin{array}{l}\text { Farmakodinamik: Menggunakan } \\
\text { kaptopril dengan spironolakton } \\
\text { berpotensi meningkatkan jumlah } \\
\text { kalium darah (drugs.com) }\end{array}$ & Moderate & 1 \\
\hline 4. & $\begin{array}{l}\text { Kaptopril dan } \\
\text { Fenobarbital }\end{array}$ & $\begin{array}{l}\text { Farmakokinetika: Fenobarbital } \\
\text { dapat menurunkan kadar kaptopril } \\
\text { dengan meningkatkan metabolism } \\
\text { (drugs.com) }\end{array}$ & Moderate & 1 \\
\hline 5. & $\begin{array}{l}\text { Paracetamol dan } \\
\text { Fenobarbital }\end{array}$ & $\begin{array}{l}\text { Farmakokinetika : Fenobarbital } \\
\text { dapat menurunkan kadar } \\
\text { paracetamol dengan meningkatkan } \\
\text { metabolisme, sehingga akan } \\
\text { meningkatkan metabolit } \\
\text { hepatotoksik (Medscape.com) }\end{array}$ & Moderate & 1 \\
\hline 6. & $\begin{array}{l}\text { Asam Folat dan } \\
\text { Fenobarbital }\end{array}$ & $\begin{array}{l}\text { Farmakokinetika: } \\
\text { Fenobarbital dapat menurunkan } \\
\text { kadar asam folat dengan } \\
\text { meningkatkan metabolisme } \\
\text { (Medscape.com) }\end{array}$ & Minor & 1 \\
\hline
\end{tabular}

Apabila dua atau lebih obat digunakan secara bersamaan, maka salah satu obat bisa mempengaruhi absorbsi, distribusi, metabolisme atau ekskresi obat lainnya, sehingga kadar plasma obat kedua dapat meningkat atau menurun, hal ini disebut dengan interaksi obat farmakokinetik. Dari hasil penelitian didapatkan frekuensi interaksi farmakokinetik mempengaruhi metabolisme sebanyak 3 kasus dengan persentase 42,9\%. Interaksi obat terjadi pada paracetamol dengan fenobarbital yang dapat menyebabkan peningkatan toksisitas dari 
paracetamol. Fenobarbital dapat menurunkan kadar paracetamol dengan meningkatkan metabolisme, sehingga akan meningkatkan metabolit hepatotoksik. Interaksi obat farmakokinetika lain yang ditemukan adalah antara kaptoril dan fenobarbital. Fenobarbital dapat menurunkan kadar kaptopril, kombinasi obat ini diterima oleh pasien usia 13 bulan yang didiagnosa bronkopneumonia dengan gagal jantung kongestif, syndrome down, serta syndrome epilepsy, yang mendapatkan terapi obat meropenem, sefiksim, parasetamol, fenobarbital, furosemid, dan mikonazol, dimana pemberian obat kaptoril dan fenobarbital dalam waktu yang bersamaan.

Berdasarkan interaksi obat farmakodinamik ditemukan 4 kasus dengan persentase $(57,1 \%)$ (Tabel 3). Salah satu interaksi obat farmakodinamik yang ditemukan dalam penelitian ini adalah kaptopril berinteraksi dengan furosemid. Efek yang ditimbulkan dari kedua kombinasi obat ini yaitu risiko hipotensi. Hal ini terjadi pada pasien dengan didiagnosa bronkopneumonia disertai penyakit jantung bawaan asianotik, autism spectrum disorder, hipotiroid kongenital, IgM selektif deficiency, infeksi IgG cytomegalovirus.

Demikian pula dengan interaksi obat farmakodinamik antara kaptopril, spironolakton dan asetazolamide. Kombinasi obat ini diterima oleh pasien usia empat bulan, dengan diagnosa bronkopneumonia disertai penyakit jantung bawaan asianotik, autism spectrum disorder, hyponatremia. Penggunaan kaptopril, dan spironolakton dalam waktu bersamaan dapat meningkatkan resiko hipotensi, sedangkan apabila kaptopril digunakan dalam waktu bersamaan dengan spironolakton berpotensi meningkatkan kadar kalium dalam darah (drugs.com).

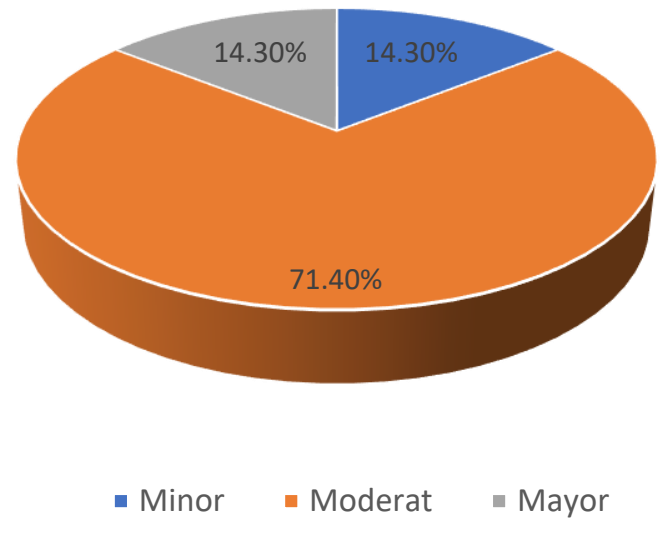

Gambar 1. Diagram angka kejadian interaksi obat berdasarkan tingkat keparahan

Berdasarkan tingkat keparahannya, interaksi obat dapat dibagi menjadi 3, yaitu minor, moderate dan major. Interaksi obat yang termasuk ke dalam tingkat keparahan minor, umumnya menimbulkan efek ringan, dan tidak mempengaruhi hasil terapi. Pada penelitian ini terdapat 1 kasus interaksi obat dengan tingkat keparahan minor dengan persentase (14,3\%). Obat-obat 
134 | Azyenela, L., dkk /Jurnal Ilmiah Farmasi (Scientific Journal of Pharmacy) Special Edition 2022, 128135

yang termasuk dalam kategori ini adalah asam folat dengan fenobarbital. Fenobarbital dapat menurunkan kadar asam folat dengan meningkatkan metabolisme, karena fenobarbital merupakan inducer enzim sehingga dia dapat menurunkan kadar obat lain dengan meningkatkan metabolisme (Medscape.com). Interaksi obat dengan tingkat keparahan ringan ini tidak memberikan dampak klinis serius pada pasien, akan tetapi pasien tetap harus dimonitoring.

Interaksi obat dengan tingkat keparahan moderat terjadi bila efek yang ditimbulkan bisa mengakibatkan terjadinya penurunan outcome klinis pasien. Dari hasil yang didapat tingkat keparahan moderate paling banyak terjadi diantara tingkat keparahan lainnya. Pada hasil didapatkan kategori moderate adalah sebanyak 5 kasus dengan persentase $(71,4 \%)$. Obat yang berpotensi mengakibatkan keparahan moderate adalah kaptopril dan furosemid. Pemberian obat kombinasi antara kaptopril dan furosemid sering digunakan secara bersamaan, namun efek yang ditimbulkannya dapat menjadi aditif dalam menurunkan tekanan darah sehingga perlu penyesuaian dosis atau tes khusus untuk penggunaan obat tersebut dalam jangka panjang (Drugs.com). Penurunan efek loop diuretic akan terjadi ketika kaptopril dan furosemid dikombinasikan. Mekanisme tersebut terjadi karena penghambatan angiotensin II dari ACE inhibitor. Monitor status cairan dan berat badan pasien ketika pasien pertama kali diberikan kombinasi kaptopril dan furosemid perlu dilakukan (Tatro, 2009).

Interakasi obat dengan tingkat keparahan moderate lainnya terjadi pada obat paracetamol dengan fenobarbital. Kombinasi obat parasetamol dengan fenobarbital, dapat menurunkan kadar paracetamol dengan meningkatkan proses metabolismenya, sehingga akan meningkatkan metabolit hepatotoksik dan menyebabkan efek samping yang serius yang dapat mempengaruhi hati (Medscape.com). Potensial hepatotoksik dari paracetamol dapat meningkat ketika fenobarbital diberikan dalam dosis yang besar, dan efek terapi parasetamol juga berkurang (Astiti, 2017). Tingkat keparahan moderate selanjutnya terjadi pada interaksi obat lain dengan obat lain antara kaptopril dan asetazolamid. Pemberian kedua obat secara bersamaan dapat meningkatkan risiko penuruanan tekanan darah secara cepat. Dengan demikian perlu dilakukan penyesuaian dosis untuk penggunaan obat tersebut dalam jangka panjang (Drugs.com).

Tingkat keparahan major pada interaksi obat dapat berpotensi mengancam jiwa atau dapat menyebabkan kerusakan permanen (Tatro, 2009). Pada tingkat keparahan kategori major didapat sebanyak 1 kasus dengan persentase (14,3\%). Kejadian interaksi obat dengan tingkat keparahan major pada penelitian ini berpotensi terjadi pada interaksi obat antara kaptopril dan spironolakton. Pemberian kaptopril bersamaan dengan spironolakton dapat meningkatkan kadar kalium dalam darah (hiperkalemia). Hiperkalemia dapat menyebabkan gejala seperti kelemahan, kebingungan, mati rasa atau kesemutan, dan denyut jantung yang tidak teratur (Drugs.com). 


\section{Kesimpulan}

Pada penelitian ini ditemukan bahwa interaksi obat yang sering terjadi pada pasien balita pneumonia rawat inap yang disertai dengan gangguan jantung bawaan di RSUP Dr. Djamil Padang adalah kombinasi kaptopril dengan furosemid.

\section{Daftar Pustaka}

Astiti PMA, Mukaddas A, Safaruddin. 2017. Identifikasi Drug Related Problems (DRPs) Pada Pasien Pediatri Pneumonia Komunitas Di Instalasi Rawat Inap RSD Madani Provinsi Sulawesi Tengah. Galenika Journal of Pharmacy; 3(1) : 57-63

Balakrishnan RK. 2014. Gambaran pneumonia pada anak di RSUP Haji Adam Malik Medan periode Januari 2011-Desember 2013 [Skripsi]. Medan: Universitas Sumatera Utara.

Baxter K. 2008. Stockley's Drug Interactions. RPS Publishing is the publishing organisation of the Royal Pharmaceutical Society of Great Britain. London.

Drugs.com, 2020. Prescription Drug Information, Interaction \& Side Effects. Tersedia https://www.drugs.com/drug_interactions.html (diakses Agustus 2020)

Hartati S, Nurhaeni N, Gayatri D. 2012. Faktor Risiko Terjadinya Pneumonia pada Anak Balita. Jurnal Keperawatan Indonesia; 15:13-20.

Herdaningsih S, Ahmad M, Keri L, Nurul A. 2016. Potensi interaksi obat-obat pada resep polifarmasi: studi retrospektif pada salah satu apotek di kota Bandung. Jurnal Farmasi Klinik Indonesia; 5(4):288-292.

Kementrian Kesehatan Indonesia RI. 2018. Riset Kesehatan Dasar. Jakarta: Balitbang kemenkes RI

Medscape, 2020, Drug Interaction Checker, (Online), (http://reference .medscape.com/druginteractionchecker).

Pediatric Formulary Committee. 2011. BNF for Children 2011-2012 (British National Formulary for Children).London: British National Formulary Publications

Price, S.A., dan Wilson, L.M. 1994. Patofisiologi: Konsep Klinis Proses-proses Penyakit, Edisi IV. Jakarta: Buku Kedokteran EGC.

Saula Ls, dan Indah LH. 2019. Potensi Interaksi Obat pada Resep Pasien Rawat Inap Pediatrik: Studi Retrospektif di Rumah Sakit Ibu dan Anak. Universitas Singaperbangsa Karawang

Soewignjo S, Gessner BD, Sutanto A, Steinhoff M, Prijanto M, Nelson C, et al. 2001. Streptococcus pneumonia Nasopharyngeal Carriage Prevalence, Serotype Distribution, and Resistance Patterns among Children on Lombok Island, Indonesia.Clinical Infection Disease.; 32:103943.

Tatro D.S. 2009. Drug Interaction Fact The Autority Drug Interactions, Fact And Comparison. Wolter Kluwers, St Louis.

World Health Organization (WHO). 2013. Hospital care for children Second edition.USA: WHO.

World Health Organization. 2013. Pocket book of Hospital Care for Children: Guidlines for Management Common Childhood Illness. 2nd ed. Geneva.

Suharjono, Yuniati, T., \& Semedi, S. (2009). Studi Penggunaan Antibiotika pada Penderita Rawat Inap Pnemonia. Majalah Ilmu Kefarmasian, 6(3), 142-155. 